\title{
Transgastric endoscopic vacuum therapy with a new open-pore film drainage device in a case of infective pancreatic necrosis
}

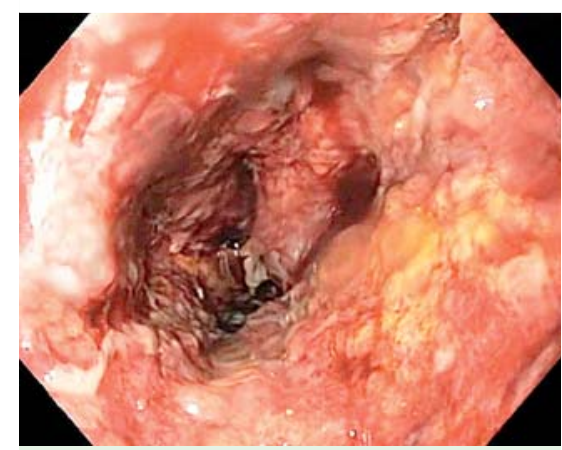

Fig. 1 Transgastric view into the retrogastric cavity after transnasal cavity drainage and endoscopic debridement had been performed for a period of 16 days.

Infected pancreatic necrosis needs to be drained; nowadays this is mostly done by endoscopic means. As yet, few cases of transgastric endoscopic vacuum therapy (EVT) have been reported [1-3]. This is the first case to be reported in which a new open-pore film drainage (OFD) device was used.

A 70-year-old man became septic because of infected pancreatic necrosis. Initially the cyst was drained with endoscopic ultrasound (EUS)-guided transgastric drainage and transnasal cavity rinsing. Endoscopic debridement was performed. After a treatment period of 16 days, a cavity of $10 \mathrm{~cm}$ in diameter that was almost free of necrosis remained ( $\bullet$ Fig. 1 ).

Subsequently, drainage treatment was continued with transgastric EVT. We used a new OFD device [4 -5]. The distal end of a drainage tube (Ventrol; $12 \mathrm{Fr} \times 120 \mathrm{~cm}$; Covidien Argyle, Dublin, Ireland) was wrapped in a very thin open-pore double-layered drainage film (Suprasorb CNP drainage film; Lohmann \& Rauscher International GmbH \& Co. KG, Rengsdorf, Germany) that was secured with a suture thread ( Fig. 2; $\bullet$ Video 1 ). The OFD device was inserted transnasally into the stomach ( Fig.3). For the placement procedure we used a standard gastroscope. The tip of the drainage tube was grasped with a forceps and pushed forward into the retrogastric cavity under endoscopic view ( $\bullet$ Fig.4a). The small diameter of the OFD device allowed easy transgastric placement without the need

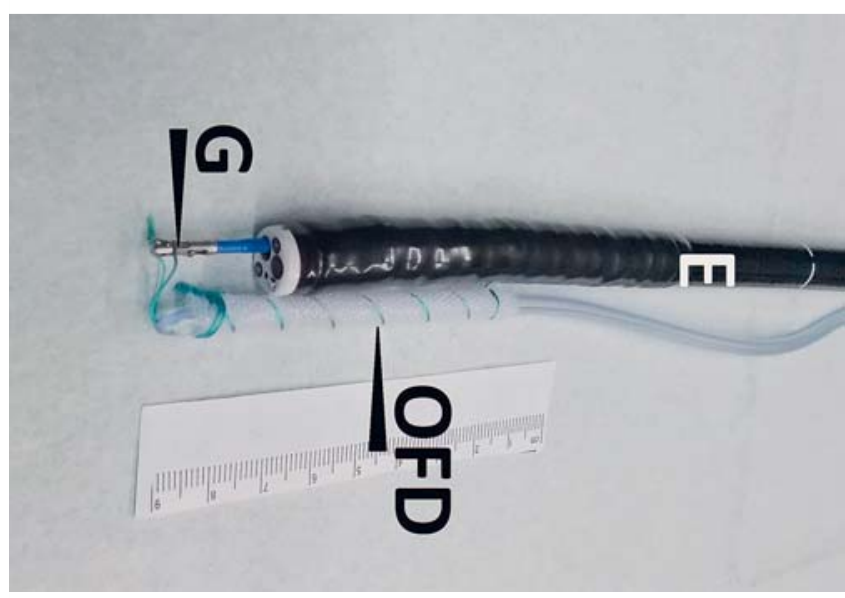

Fig. 2 The new openpore film drainage (OFD) device: the distal end of a drainage tube is wrapped with an open-pore film.

E, endoscope; G, grasper.

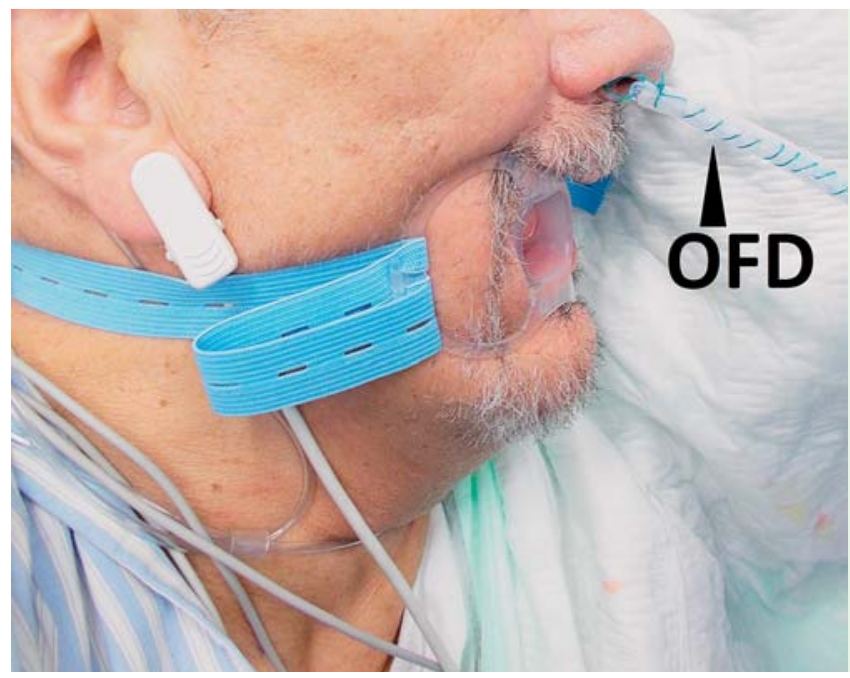

Fig. 3 The open-pore film drainage (OFD) device is inserted transnasally.

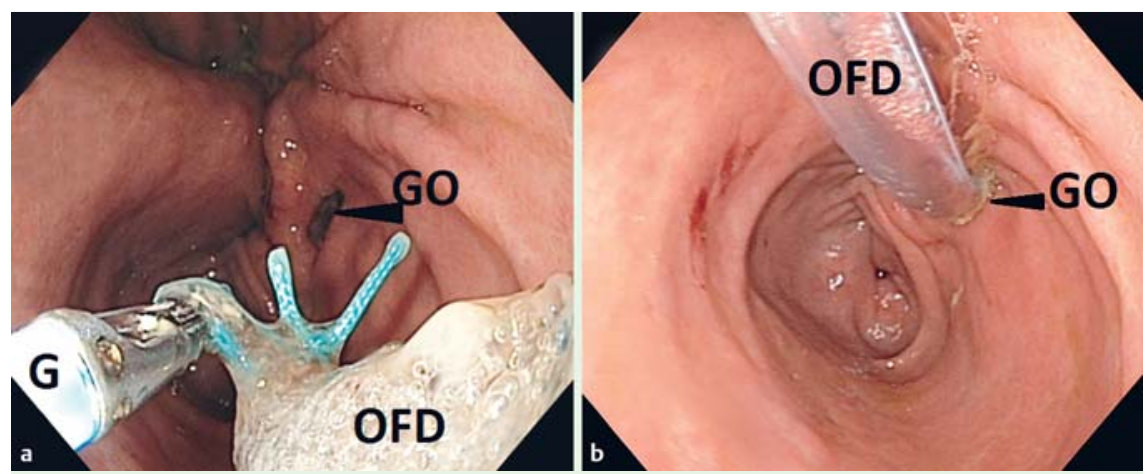

Fig. 4 Endoscopic views showing: a the open-pore film drainage (OFD) device grasped by an endoscopic grasper (G) in the stomach (GO, gastric opening): $\mathbf{b}$ the OFD device with its film-covered distal end completely inserted into the retrogastric cavity so that a vacuum can be applied.

for dilation of the gastric opening ( $\bullet$ Fig. 4 b; Video 1 ).

After application of a vacuum with an electronic vacuum device (KCI V.A.C. Free- dome: KCI USA Inc., San Antonio, Texas, USA; setting: $-75 \mathrm{mmHg}$, continuous, intensity 10) the cyst shrank immediately around the OFD device. Liquids were 


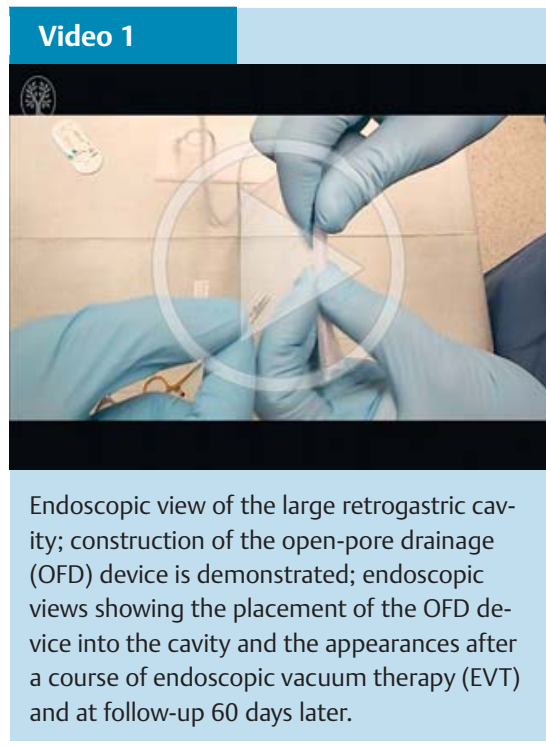

drained in an intraluminal direction and the transmural defect was closed simultaneously.

The total treatment period of EVT was 10 days, during which time oral intake of fluids and soft diet was possible. The OFD device was changed twice on days 3 and 7 , with the OFD device being removed by gently pulling the tube and a thin nasal gastroscope being used for transgastric endoscopy. Even at the first OFD device change on day 3 , the cavity had already reduced to a small canal and pimpled suction patterns were seen on the tissues (৫ Fig.5).

Follow-up endoscopies, after the 10 days of EVT had been completed, showed small amounts of secretion at the gastric opening for the next few days. A final endoscopy and EUS 60 days after the end of treatment showed complete healing with the cavity no longer visible.

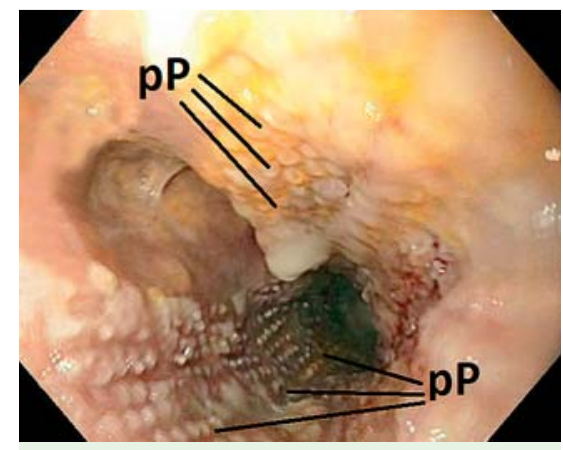

Fig. 5 Transgastric view of the cavity after 3 days of vacuum therapy, following removal of the open-pore film drainage (OFD) device, showing a shrunken cavity consisting of a small canal with the typical pimpled pattern (pP) visible, providing evidence of effective vacuum suction.

\section{Endoscopy_UCTN_Code_TTT_1AR_2AI}

Competing interests: Gunnar Loske is a consultant for Lohmann \& Rauscher $\mathrm{GmbH}$. The other authors have no interests to declare.

\section{Gunnar Loske ${ }^{1}$, Tobias Schorsch ${ }^{1}$, Olaf Gobrecht ${ }^{2}$, Eckhard Martens ${ }^{2}$, Frank Rucktäschel ${ }^{2}$}

${ }^{1}$ Department for General, Abdominal, Thoracic and Vascular Surgery, Katholisches Marienkrankenhaus Hamburg gGmbH, Hamburg, Germany

2 Department for Medical Oncology and Hematology, Gastroenterology and Infectious Diseases, Katholisches Marienkrankenhaus Hamburg gGmbH, Hamburg, Germany

\section{Acknowledgments}

$\nabla$

We would like to thank the nursing staff of the interdisciplinary endoscopic unit of Marienkrankenhaus Hamburg for their excellent technical assistance.

\section{References}

1 Wallstabe I, Tiedemann A, Schiefke I. Endoscopic vacuum-assisted therapy of an infected pancreatic pseudocyst. Endoscopy 2011; 43 (Suppl. 02): E312 -E313

2 Wallstabe I, Tiedemann A, Schiefke I. Endoscopic vacuum-assisted therapy of infected pancreatic pseudocyst using a coated sponge. Endoscopy 2012; 44 (Suppl. 02): E49-E50

3 Wedemeyer J, Kubicka S, Lankisch TO et al. Transgastrically placed endoscopic vacuum-assisted closure system as an addition to transgastric necrosectomy in necrotizing pancreatitis (with video). Gastrointestinal Endosc 2012; 76: 1238-1241

4 Loske $G$, Schorsch $T$, van Ackeren $V$ et al. Endoscopic vacuum therapy in Boerhaave's syndrome with open-pore polyurethane foam and a new open-pore film drainage. Endoscopy 2015; 47: E410-E411

5 Loske G, Rucktäschel F, Schorsch T et al. Successful endoscopic vacuum therapy with new open-pore film drainage in a case of iatrogenic duodenal perforation during ERCP. Endoscopy 2015; 47 (Suppl. 01): E577-E578

\section{Bibliography}

DOI http://dx.doi.org/

10.1055/s-0042-106576

Endoscopy 2016; 48: E148-E149

(c) Georg Thieme Verlag KG

Stuttgart · New York

ISSN 0013-726X

\section{Corresponding author \\ Gunnar Loske, MD}

Department for General, Abdominal, Thoracic and Vascular Surgery

Katholisches Marienkrankenhaus Hamburg $\mathrm{gGmbH}$

Alfredstrasse 9

22087 Hamburg

Germany

Fax: +49-40-25461400

loske.chir@marienkrankenhaus.org 